\title{
Variation in species diversity and functional traits of sponge communities near human populations in Bocas del Toro, Panama
}

Cole G Easson, Kenan O Matterson, Chris J Freeman, Stephanie K Archer, Robert W Thacker

Recent studies have renewed interest in sponge ecology by emphasizing the functional importance of sponges in a broad array of ecosystem services. Many critically important habitats occupied by sponges face chronic stressors that might lead to alterations in their diversity, relatedness, and functional attributes. We addressed whether proximity to human activity might be a significant factor in structuring sponge community composition, as well as potential functional roles, by monitoring sponge diversity and abundance at two structurally similar sites that vary in distance to areas of high coastal development in Bocas Del Toro, Panama. We surveyed sponge communities at each site using belt transects and differences between two sites were compared using the following variables: (1) sponge species richness, Shannon diversity, and inverse Simpson's diversity; (2) phylogenetic diversity; (3) taxonomic and phylogenetic beta diversity; (4) trait diversity and dissimilarity; and (5) phylogenetic and trait patterns in community structure. We observed significantly higher sponge diversity at Punta Caracol, the site most distant from human development $(\sim 5 \mathrm{~km})$. Although phylogenetic diversity was lower at Saigon Bay, the site adjacent to a large village including many houses, businesses, and an airport, the sites did not exhibit significantly different patterns of phylogenetic relatedness in species composition. However, each site had a distinct taxonomic and phylogenetic composition (beta diversity). In addition, the sponge community at Saigon included a higher relative abundance of sponges with high microbial abundance and high chlorophyll a concentration, whereas the community at Punta Caracol had a more even distribution of these traits, yielding a significant difference in functional trait diversity between sites. These results suggest that lower diversity and potentially altered community function might be associated with proximity to human populations. This study highlights the importance of evaluating functional traits and phylogenetic diversity in addition to common diversity metrics when assessing potential environmental impacts on benthic communities. 
Variation in species diversity and functional traits of sponge communities near human populations in Bocas del Toro, Panama

Cole G. Easson ${ }^{1 *}$, Kenan O. Matterson ${ }^{1}$, Christopher J. Freeman ${ }^{2}$, Stephanie K. Archer ${ }^{3}$, Robert W. Thacker ${ }^{4}$

${ }^{1}$ Department of Biology, University of Alabama at Birmingham, Birmingham, Alabama, 9 USA

11 2Smithsonian Marine Station, Fort Pierce, Florida, USA

$12{ }^{3}$ Department of Applied Ecology, North Carolina State University, Raleigh, North Carolina,

13 USA

$14{ }^{4}$ Department of Ecology and Evolution, Stony Brook University, Stony Brook, New York, USA

*Corresponding author is Cole Easson: email: ceasson@nova.edu

Abstract 
Recent studies have renewed interest in sponge ecology by emphasizing the functional importance of sponges in a broad array of ecosystem services. Many critically important habitats occupied by sponges face chronic stressors that might lead to alterations in their diversity, relatedness, and functional attributes. We addressed whether proximity to human activity might be a significant factor in structuring sponge community composition, as well as potential functional roles, by monitoring sponge diversity and abundance at two structurally similar sites that vary in distance to areas of high coastal development in Bocas Del Toro, Panama. We surveyed sponge communities at each site using belt transects and differences between two sites were compared using the following variables: (1) sponge species richness, Shannon diversity, and inverse Simpson's diversity; (2) phylogenetic diversity; (3) taxonomic and phylogenetic beta diversity; (4) trait diversity and dissimilarity; and (5) phylogenetic and trait patterns in community structure. We observed significantly higher sponge diversity at Punta Caracol, the site most distant from human development $(\sim 5 \mathrm{~km})$. Although phylogenetic diversity was lower at Saigon Bay, the site adjacent to a large village including many houses, businesses, and an airport, the sites did not exhibit significantly different patterns of phylogenetic relatedness in species composition. However, each site had a distinct taxonomic and phylogenetic composition (beta diversity). In addition, the sponge community at Saigon included a higher relative abundance of sponges with high microbial abundance and high chlorophyll $a$ concentration, whereas the community at Punta Caracol had a more even distribution of these traits, yielding a significant difference in functional trait diversity between sites. These results suggest that lower diversity and potentially altered community function might be associated with proximity to human populations. This study highlights the importance of evaluating functional traits and 
48 phylogenetic diversity in addition to common diversity metrics when assessing potential

49 environmental impacts on benthic communities.

50 Keywords: Porifera, Community Ecology, Anthropogenic influences, Microbial symbionts,

51 Photosynthesis

52

53

54

55

56

57

\section{Introduction}

Coral reefs are critical and dynamic habitats that provide a variety of important ecosystem services that support local economies and international industries around the world (Moberg and Folke 1999, Mumby et al. 2008). Historically, scleractinian corals have provided the structural framework for many of these complex reef networks (Aronson et al. 2001). However, in recent decades, reefs worldwide have experienced a marked decline in the abundance of reef-building corals due to multiple stressors including marine pathogens, overfishing of herbivores, and coastal eutrophication (Hughes 1994, Lapointe 1997, Hughes and Connell 1999, Jackson et al. 2001, Harvell et al. 2007). Caribbean reefs exemplify this trend, as many of these reef systems have undergone drastic phase shifts, resulting in the dominance of fleshy macroalgae in place of hard corals (McCook 1999, Maliao, Turingan \& Lin, 2008, Dudgeon et al. 2010). Along with altered community composition, structure and function (Norström et al. 2009), these new "stable" states provide fewer ecosystem services (Brock and Carpenter 2006, Carpenter and Brock 2006). Healthy reefs are typically characterized as structurally complex habitats that act as refuges for a variety of species including juvenile fish and invertebrates, effectively increasing the diversity and abundance of the associated community (Graham et al. 2006). In contrast, the reduced habitat complexity of macroalgal 
communities supports lower species diversity and productivity across numerous trophic levels (McCook 1999, Jones et al. 2004).

In addition to increased macroalgal cover, sessile macro-invertebrates, like sponges and gorgonians, are often more abundant on degraded reefs (Maliao, Turningan \& Lin, 2008). This increased sponge abundance may have important ecological implications for these communities (Bell et al. 2013), as numerous sponge species are known to perform critical functional roles on shallow reefs. For instance, sponges directly contribute to energy cycling on reefs by efficiently clearing dissolved organic carbon (Yahel et al. 2003, de Goeij et al. 2013), bacteria (Reiswig 1971, Pile, Patterson \& Witman, 1997) and pathogens from the water column, incorporating these energy sources into the benthic system (Hadas et al. 2006). Moreover, by hosting diverse and often abundant microbial symbionts, sponges contribute to primary productivity (photosynthesis) and nutrient cycling on the reef (Wilkinson and Fay 1979, Wilkinson 1983, 1992, Díaz and Ward 1997), even though microbial community composition and, subsequently, functional roles, are highly variable among species (Easson and Thacker 2014, Freeman, Easson \& Baker, 2014). Thus, as sponge abundance increases throughout the Caribbean (Nyström, Folke \& Moberg, 2000, Norström et al. 2009) and populations of large species such as the giant barrel sponge, Xestospongia muta, increase in some regions (increased by 46\% from 2000 to 2006 in the Florida Keys; McMurray, Henkel \& Pawlik, 2010), it is likely that shifts in nutrient cycling and ecosystem function are also occurring across degraded reef systems (Díaz and Rützler 2001, Wulff 2001, de Goeij et al. 2013).

Although overall sponge richness and total biomass may be positively correlated with anthropogenic stressors (Zea 1994), some sponge species may be just as susceptible to alterations in the chemical, biological and physical characteristics of the surrounding environment as corals 
94 (Fang et al. 2014). For example, elevated concentrations of organic pollutants can influence

95

96

97

98

99

100

101

102

103

104

105

106

107

108

109

110

111

112

113

114

115

116

sponge community structure by altering species diversity (Alcolado 2007, Powell et al. 2014).

Based on these data, we would predict that sponge community diversity and species composition might change across a gradient of anthropogenic stressors, but the specific response is potentially variable. Recent work has highlighted the need to move beyond simply measuring species diversity, showing that an organism's contribution to a habitat may be more important than its presence or absence (Cadotte 2011, Safi et al. 2011, Stuart-Smith et al. 2013, 2015). This principle is especially relevant in tropical ecosystems characterized by high diversity and often a high degree of functional redundancy (Stuart-Smith et al. 2013). Sponges represent an ideal group on coral reefs to study shifts in organismal contribution to ecosystem function, because they are prolific reef-builders, have a range of functional behaviors, and contribute a variety of crucial services to reef environments (Díaz and Rützler 2001, de Goeij et al. 2013).

The Bocas del Toro archipelago on the Caribbean coast of Panama includes numerous islands, mangrove cays, peninsulas, fringing reefs and seagrass beds that surround shallow bays with historically high coral cover (Collin 2005). The region receives high annual rainfall (3-5m), resulting in variations in temperature, salinity, sedimentation and turbidity (Kaufmann and Thompson 2005). In addition, while the Bocas del Toro region historically was home to several indigenous communities, the areas around Bocas Town and Saigon Village have recently experienced rapid large population growth (Figure 1). This rapid population growth combined with high tourism rates, substandard public infrastructure (e.g. sewers), and deforestation has contributed to increased run-off and pollution of the near shore environment (Aronson et al. 2004). For example, there have been reports of "black water" outflow (sewage, road pollution and solid waste dumping) into Saigon Bay. The concentration of human activities in the Bocas 
117 del Toro region implies that some local reef communities may be negatively impacted by chronic

118 fluctuations in water quality, while other reefs more distant from human development may be

119 exposed to these anthropogenic stressors less frequently (D’Croz, Del Rosario, \& Gondola, 2005,

120 Gochfeld, Schloder \& Thacker, 2007).

121 The goal of our study was to build on the research of Gochfeld, Schloder \& Thacker,

122 (2007), who reported signs of sponge community variation that included lower diversity and

123 higher disease prevalence near human settlement. Additionally, because measurements of alpha

124 diversity can overlook important genetic and/or functional variability among species in the

125 community, we also assessed potential variation in phylogenetic diversity, taxonomic and

126 phylogenetic composition (beta diversity), and functional traits between sites, with the goal of

127 forming testable hypotheses for how sponge community variation may translate to meaningful

128 functional variation in communities of these increasingly dominant benthic organisms.

129 Methods

130 Field sites. To assess potential sponge assemblage differences related to proximity to human

131 development, we conducted belt transects adjacent to concentrated human settlement around

132 Saigon Bay, an area where about 150 houses, an airport and several businesses are in close

133 proximity to shore ( $\mathrm{n}=9$, Saigon), and $\sim 5 \mathrm{~km}$ away from town where only a few houses are

134 located ( $\mathrm{n}=10$, Punta Caracol, Figure 1). Surveys conducted near Saigon Bay were not in the

135 exact same location as Gochfeld, Schloder \& Thacker, (2007), whose site was located within the

136 bay, likely subjecting it to naturally different environmental conditions. In the current study we

137 conducted surveys at the mouth of Saigon Bay to better standardize reef structure between sites.

138 Surveys were conducted at these sites in August 2012 and April 2014. Survey sites were similar

139 in depth, exposure direction, and distance from shore. All transect data were collected on 
140 SCUBA at a depth of 5-7 $\mathrm{m}$ along the general axis of the reef with a minimum distance of $10 \mathrm{~m}$

141 between each transect. All specimen collection for this study was performed in accordance with

142 a collection permit from the government of Panama, issued to Robert W. Thacker (resolution

143 DGOMI-PICFC No. 36 issued on July 4, 2012).

144

145 Sponge richness and diversity Sponge diversity and abundance were characterized by counting 146 individuals that fell within $1 \mathrm{~m}$ of the transect line (i.e., creating $10 \mathrm{~m} \times 2 \mathrm{~m}$ belt transects). A

147 total area of $200 \mathrm{~m}^{2}$ and $180 \mathrm{~m}^{2}$ was surveyed at Punta Caracol and Saigon, respectively. Each

148 sponge was identified to the lowest possible taxonomic level. For sponges that were

149 unidentifiable in situ, voucher specimens were collected and identified in the laboratory

150 following spicule and fiber preparations. Using the R package vegan (Oksanen et al. 2007), we

151 calculated three univariate measures of sponge diversity for each transect at each survey site:

152 species richness $(S)$, the Shannon index $\left(H^{\prime}\right)$, and the inverse Simpson's index $(D)$. We compared

153 each of these metrics between the two sites using a two-sample t-test.

Phylogenetic reconstruction. Phylogenetic relatedness among surveyed sponge species was assessed using a phylogeny constructed from a partitioned alignment of gene sequences from

157 Genbank coding for the small (18S) and large (28S) nuclear ribosomal subunits, which are common markers used for molecular identification of sponge species (Redmond et al. 2013,

159 Thacker et al. 2013, Table S1). One sponge species, Verongula reiswigi, was not represented in

160 Genbank, and we obtained sequence from vouchers representing this species as part of the 161 current study (Supplemental methods). 
162 We reconstructed a phylogeny for all sponge species except Niphates caycedoi, for which we

163 were unable to obtain sequence information. This species was rare, with only four individuals of

164 this species found at one site. This species was excluded from phylogenetic analysis. For each

165 gene, sequences were aligned using the default options of MAFFT 7.017 (Katoh et al. 2002) in

166 the program Geneious (version 6.1.8, Biomatters Limited). We concatenated the two alignments,

167 treating them as two separate partitions with independent models of sequence evolution. We

168 implemented a relaxed-clock model in MrBayes version 3.2.1 (Ronquist et al. 2012), using the

169 CIPRES computational resources (Miller, Pfeiffer \& Schwartz, 2010), and following

170 recommended best practices for implementing partitioned analysis (Wiens and Morrill 2011,

171 Kainer and Lanfear 2015). We constrained sponges in the genus Plakortis as an outgroup, using

172 the independent gamma rate relaxed clock model with a birth-death process (Supplemental File

173 1, Aris-Brosou and Yang 2003). We included three parallel runs of 10 million generations, each

174 using four Markov chains and sampling every 100 generations. A consensus phylogeny of the

175 three parallel runs was summarized following a burn-in of 25\% (Supplemental Figure 1).

Phylogenetic relatedness and patterns of diversity. We assessed phylogenetic diversity by

calculating Faith's phylogenetic diversity (PD), using the R package picante (Kembel et al.

2010). Faith's PD measures the total branch length spanned by the sub-tree from each

al. 2010). Additionally, Faith's PD relaxes the diversity measurement assumption that all species and Chao 2013). Phylogenetic diversity patterns (clustering, dispersion, or random) were assessed by measuring the mean pairwise distance (MPD) and mean nearest taxon distance 
185 (MNTD) scaled to the standard effect size among sponges within each site, accepting the default 186 options in the models. MPD calculates the mean distance between two randomly chosen 187 individuals in the community. Significant clustering measured by MPD implies a higher 188 presence of species related to one another through interior nodes (away from the tips of the phylogeny) belonging to broader phylogenetic groups. MNTD calculates the mean distance separating one individual from its closest relative. MNTD describes clustering at the tips of the tree, and significant clustering by this metric indicates a higher presence of closely related species connected by nodes closer to the tips of the phylogeny. For both MPD and MNTD, we assessed differences in phylogenetic diversity patterns using two t-tests. We used a two-sample ttest to assess differences between sites, and a one-sample t-test to test whether each site differed from a null hypothesis of random phylogenetic relatedness $(\mu=0$, Kembel et al. 2010, Kembel and Cahill Jr 2011).

Beta-diversity analysis. We assessed taxonomic beta diversity patterns between sites by calculating Bray-Curtis dissimilarity (BCD) among all transects. We also calculated phylogenetic beta diversity among all transects, which compares MPD and MNTD between two individuals selected from different sites as opposed to individuals within the same site as previously measured (Kembel et al. 2010, Kembel and Cahill 2011). To compare taxonomic and phylogenetic dissimilarity between sites, we used the function adonis in the $\mathrm{R}$ package vegan (Oksanen et al. 2007). We used similarity percentage analysis (SIMPER) to determine the proportional contribution of each species to BCD.

Functional trait diversity and dissimilarity. We evaluated two traits (1: microbial abundance and 2: chlorophyll $a$ concentration) that are often associated with the functional roles of sponges in coral reef communities. Microbial abundance is often linked to water filtration rate. Low 
208 microbial abundance sponges (LMA) typically have higher pumping rates and thus filter more 209 particulate organic matter (POM) from the water column. In contrast, high microbial abundance

210 (HMA) sponges often have lower pumping rates but are able to access key inorganic nutrient

211 sources through their symbionts. Photosymbionts represent a unique class of sponge symbionts

212 that provide access to autotrophic nutrition and other key inorganic nutrients. Abundance of

213 photosymbionts is often estimated by measuring chlorophyll $a$ concentration within sponge

214 tissue (e.g. Gochfeld et al. 2012, Easson et al. 2014, Freeman, Easson \& Baker, 2014). While

215 these two traits are often related, we assessed both traits to tease apart potential differences

216 between HMA and low photosymbiont abundance (e.g. Agelas conifera, Aiolochroia crassa,

217 etc.), which might occur in higher abundance at sites with lower irradiance and higher inorganic

218 nutrients. Sponges of different classifications, with respect to these two traits, show distinct

219 biogeochemical cycling in carbon and nitrogen cycling, which might impact the larger reef

220 community (Freeman, Easson \& Baker, 2014). We treated microbial abundance as a binary

221 factor, as data for absolute microbial abundance in sponges is limited, categorizing sponges as

222 either high microbial abundance (HMA) or low microbial abundance (LMA) based on their

223 previously published designation (Oksanen et al. 2007, Weisz et al. 2007, Weisz, Lindquist \&

224 Martens, 2008, Gloeckner et al. 2014). We treated chlorophyll $a$ concentration in sponge tissue

225 as a continuous variable based on values in Erwin and Thacker (2007). The species Svenzea

226 cristinae was not analyzed in this previous survey, thus vouchers of this sample were collected

$227 \quad(\mathrm{n}=8)$ and chlorophyll $a$ concentration was measured using the same methodology as Erwin and

228 Thacker (2007) (Supplemental methods). We initially compared differences in these two traits

229 between sites using a two-sample t-test, assessing the proportion of HMA/LMA or High/Low

230 chlorophyll $a$ sponges (High/Low chlorophyll $a$ defined in Erwin and Thacker 2007) between 
231 sites. We then calculated measurements of trait diversity similarly to phylogenetic diversity by

232 calculating the pairwise distance among species using the values for the measured functional

233 traits (microbial abundance and chlorophyll $a$ concentration) to create a distance matrix, which

234 allowed for comparisons of dissimilarity among co-occurring species and between sites (Kembel

235 and Cahill 2011). We compared trait diversity between sites using a two-sample t-test to test for

236 site differences and a one-sample t-test to examine whether either site differed from a null

237 hypothesis for random trait patterns. We assessed functional trait beta diversity similarly to

238 phylogenetic beta diversity (comparing trait distances between two individuals from different

239 sites, Kembel and Cahill 2011), using the function adonis in the R package vegan (Oksanen et al.

240 2007).

241 Overlap in beta diversity metrics. To investigate potential overlap among our metrics of

242 community dissimilarity, we used Mantel tests to determine whether BCD, phylogenetic

243 dissimilarity, and trait dissimilarity were correlated.

\section{Results}

245 Field sites. Transects at Saigon and Punta Caracol contained an average of 260 and 194

246 individual sponges, representing $17 \pm 0.7$ and $22 \pm 1($ mean $\pm \mathrm{SE})$ sponge species per $20 \mathrm{~m}^{2}$,

247 respectively. Species richness at these two sites combined for a total of 40 sponge species. Two

248 sponges from the genus Aplysina were the most abundant members of these sponge communities

249 with 681 and 587 individuals of $A$. fulva and A. cauliformis, respectively, pooling data from both

250 sites. These two species accounted for approximately $28 \%$ of the total sponge individuals at each

251 site. Other notably abundant species were Chondrilla caribensis, Mycale laevis, Svenzea

252 cristinae, Niphates erecta, and Verongula rigida. Eight species (35\% of unique sponge species) 
253 were unique to Punta Caracol, while 2 species (11\% of unique sponge species) were unique to

254 Saigon. These sponges were present at lower abundances within their respective community,

255 with none of these less common species having more than 12 individuals in the entire dataset.

256 Sponge richness and diversity. Species richness of individual transects ranged from 12 to 24

257 species. All three diversity indices were significantly different between the two sites: Species

258 richness $(S)($ mean \pm SE: $17.3 \pm 1.0$ and $22.1 \pm 0.7$ for Saigon and Punta Caracol, respectively; t-test:

$259 \mathrm{t}=3.99, \mathrm{df}=14.43, \mathrm{P}=0.001)$, Shannon Index $\left(H^{\prime}\right)($ mean $\pm \mathrm{SE}: 2.2 \pm 0.06$ and $2.6 \pm 0.05$ for

260 Saigon and Punta Caracol, respectively; $\mathrm{t}-$ test: $\mathrm{t}=4.44, \mathrm{df}=16.63, \mathrm{P}<0.001$ ), and inverse

261 Simpson's Index (D) (mean \pm SE: $7.0 \pm 0.5$ and 10.2 \pm 0.7 for Saigon and Punta Caracol,

262 respectively; $\mathrm{t}$-test: $\mathrm{t}=3.64, \mathrm{df}=16.42, \mathrm{P}=0.002$ ). Saigon on average had lower species

263 richness and community evenness compared to Punta Caracol

264 Phylogenetic relatedness and patterns of diversity. In addition to the lower species diversity at

265 Saigon, we observed significantly lower phylogenetic diversity (Faith's PD; $3.11 \pm 0.11$ for

266 Saigon and $3.45 \pm 0.09$ for Punta Caracol; $\mathrm{t}$-test, $\mathrm{t}=2.45, \mathrm{df}=15.39, \mathrm{P}=0.027$ ), indicating

267 differences in the total branch length spanned by the sub-tree from each community. We

268 observed no differences in MPD, between our two sites ( $\mathrm{t}$-test, $\mathrm{t}=0.15, \mathrm{df}=12.52, \mathrm{P}=0.873)$.

269 Although Punta Caracol displayed a pattern of random MPD (one-sample t-test, $\mathrm{t}=-1.29$, $\mathrm{df}=9$,

$270 \mathrm{P}=0.229$ ), Saigon showed a pattern of MPD clustering (one-sample t-test, $\mathrm{t}=-3.22, \mathrm{df}=8, \mathrm{P}=$

271 0.012). These results imply that Saigon has a slightly higher presence of more closely related

272 species than Punta Caracol. We observed no significant differences in MNTD between our sites

273 (t-test, $\mathrm{t}=-1.40, \mathrm{df}=12.05, \mathrm{P}=0.186$ ), and each site displayed a random distribution of MNTD

274 (one-sample t-test, $\mathrm{t}=-0.99, \mathrm{df}=8, \mathrm{P}=0.348$ and $\mathrm{t}=-1.94, \mathrm{df}=9, \mathrm{P}=0.084$ for Saigon and

275 Punta Caracol, respectively). These results indicate that while phylogenetic diversity, often 
276 correlated with species richness, is lower at Saigon, these two sites do not show significantly

277 different patterns of phylogenetic relatedness in species composition. Given the narrow

278 geographic range of this study $(\sim 5 \mathrm{~km})$, it is possible that these patterns of phylogenetic

279 diversity may be more indicative of the regional sponge fauna instead of differences between 280 sites.

Beta-diversity analysis. We observed significant differences in beta diversity for taxonomic

282 (adonis, $\mathrm{F}=8.39, \mathrm{df}=1, \mathrm{R}^{2}=0.33, \mathrm{P}=0.001$, Figures 2 and $3 \mathrm{a}$ ) and MPD phylogenetic

283 dissimilarity (adonis, $\mathrm{F}=1.53, \mathrm{df}=1, \mathrm{R}^{2}=0.083, \mathrm{P}=0.001$, Figure $3 \mathrm{~b}$ ), but not for MNTD

284 phylogenetic dissimilarity (adonis, $\mathrm{F}=0.69, \mathrm{df}=1, \mathrm{R}^{2}=0.04, \mathrm{P}=0.476$, Figure $3 \mathrm{c}$ ) between

285 sites. SIMPER analysis revealed that 5 sponge species comprised about $50 \%$ of the BCD

286 between the two sites, including: Svenzea cristinae (16\%), Aplysina cauliformis (10\%), Aplysina

287 fulva (9\%), Haliclona walentinae (8\%), and Chondrilla caribensis (7\%), all of which were found

288 in higher relative abundance at Saigon (Figure 2). Moreover, the SIMPER results demonstrate

289 that the lower species $D$ at Saigon was due to the increased abundance of a few sponge species.

290 Functional trait diversity and dissimilarity. Analysis of trait proportions between sites revealed

291 that Saigon had a higher proportion of HMA ( $\mathrm{t}$-test: $\mathrm{t}=-2.63, \mathrm{df}=16.41, \mathrm{P}=0.02)$ and high

292 chlorophyll $a(\mathrm{t}$-test: $\mathrm{t}=-9.00, \mathrm{df}=16.50, \mathrm{P}<0.001)$ sponges, and the proportions of these two

293 traits were correlated (Pearson's correlation, $\mathrm{r}=0.62, \mathrm{df}=17, \mathrm{P}=0.005$ ). Trait diversity was

294 significantly different between our two sites ( $\mathrm{t}$-test, $\mathrm{t}=3.34$, $\mathrm{df}=10.68, \mathrm{P}<0.001)$. Traits were

295 significantly more clustered at Saigon (one-sample t-test, $\mathrm{t}=-2.49, \mathrm{df}=8, \mathrm{P}=0.044$ ), whereas

296 traits were more evenly distributed at Punta Caracol (one-sample $\mathrm{t}$-test, $\mathrm{t}=2.73, \mathrm{df}=9, \mathrm{P}=$

297 0.006, Figure 3d). Species from Punta Caracol had a broad range of chlorophyll $a$ concentrations

298 and microbial abundances, while species at Saigon were only represented by a subset of this 
299 range. Trait beta diversity between sites was significantly different (adonis, $\mathrm{F}=82.264$, $\mathrm{df}=1$,

$300 \mathrm{R}^{2}=0.83, \mathrm{P}=0.002$ ) and explained approximately $83 \%$ of the variation among transects.

301 Overlap in beta diversity metrics. Mantel tests indicated that BCD taxonomic dissimilarity was

302 significantly correlated with MPD phylogenetic dissimilarity (Mantel: $r=0.48, P=0.001$ ),

303 MNTD phylogenetic dissimilarity (Mantel: $\mathrm{r}=0.51, \mathrm{P}=0.001$, and trait dissimilarity (Mantel: $\mathrm{r}$

$304=0.24, \mathrm{P}=0.004)$. Phylogenetic MPD (Mantel: $\mathrm{r}=0.22, \mathrm{P}=0.010)$ and MNTD $($ Mantel: $\mathrm{r}=$

$3050.27, \mathrm{P}=0.005)$ dissimilarity were correlated with trait dissimilarity.

306

307

308

309

310

311

312

313

314

315

316

317

318

319

320

\section{Discussion}

This study identified clear differences in sponge species diversity and richness between Saigon and Punta Caracol, supporting previous findings from Gochfeld, Schloder \& Thacker, (2007), who attributed this variation to chronic anthropogenic influence. Building on these results, we also observed significantly lower phylogenetic diversity at Saigon, and demonstrated that each site had a distinct taxonomic and phylogenetic community structure (Figure 2). This variation in community structure resulted in contrasting trait diversity between sites, with Saigon dominated by sponges with high chlorophyll $a$ concentrations and high microbial abundance.

The region of Almirante Bay in Bocas del Toro, Panama is characterized by high sponge biodiversity with over 120 species found in reef, seagrass, and mangrove habitats (Diaz 2005), despite episodic heavy rainfall resulting in severe freshwater runoff, sedimentation, and low tidal flushing (D’Croz, Del Rosario, \& Gondola, 2005). Much of the development in the area has little or no sewage treatment, and many residences and businesses are built adjacent to or over the water (Figure 1, Collin 2005). Thus, many near-shore environments in this area are heavily influenced by human activity (Aronson et al. 2004), and abundant human debris is often 
321 observed floating and at depth in these areas (Easson personal observation). Although sponges

322 are considered to be sensitive to environmental stressors (Gochfeld, Schloder \& Thacker, 2007),

323 including elevated nutrient concentrations (Easson et al. 2014, but see Gochfeld et al. 2012), a

324 factor associated with poor sewage treatment, the Bocas del Toro region maintains high sponge

325 diversity (Diaz 2005). In contrast to the high diversity and abundance of sponges in the region,

326 coral communities have experienced a marked decline associated with changes in water quality,

327 concurrent with increases in human settlement in the region (Guzman 2003, Aronson et al.

328 2004).

By coupling heterotrophic filter-feeding with microbial metabolic pathways afforded by their symbionts, many sponges are able to utilize a wide range of nutrient sources that likely contribute to their proliferation in a wide range of habitats, even in anthropogenically-stressed areas where corals are in decline (Aronson et al. 2004, Diaz 2005). However, changes in sponge community diversity and composition among sites may indicate chronic environmental stress. Gochfeld, Schloder \& Thacker, (2007) found distinct shifts in composition and lower diversity associated with proximity to human development. Likewise, the current study demonstrated that sponge assemblages in close proximity to human populations were less diverse and dominated by a small number of species. When we looked beyond richness and diversity, we observed that the community at Saigon contained lower genetic diversity, selecting for more distantly related species belonging to broader phylogenetic groups. Differences in assemblage composition were driven mainly by the high abundance of Svenzea cristinae and Haliclona walentinae at Saigon; these species were nearly absent at Punta Caracol. Additionally, Saigon showed a higher abundance of Aplysina cauliformis, Aplysina fulva, and Chondrilla caribensis. Interestingly, 
344 photosymbiont abundance. In contrast to previous surveys in the area (Gochfeld, Schloder \&

345 Thacker, 2007), we found that the number of individuals increased at sites in close proximity to

346 human development. This result may be skewed by the occurrence of many small individuals of

347 Svenzea cristinae at Saigon (mean $=47$ per transect) as compared to Punta Caracol (mean $=5$

348 per transect). While estimates of sponge biomass or volume are necessary to definitively

349 measure changes in sponge abundance across sites (Wulff 2001), the number of individuals or

350 species is often related to sponge biomass measurements (Wulff 2006, 2013).

351 While metrics such as diversity and richness have been widely used to estimate

352 community health in many marine systems (e.g. Witman, Etter \& Smith, 2004, Schlacher et al.

353 2007, Hewitt, Thrush \& Dayton, 2008), these metrics capture only a small part of potential

354 changes and do not consider the functional variability of species are within a habitat (Cadotte

355 2011, Gotelli and Chao 2013, Stuart-Smith et al. 2015). Sponges exhibit a wide range of

356 functional behaviors, and aside from filter feeding, many of the functional roles that sponges fill

357 are tied to the diverse and abundant microbial communities that they host. Both of the traits

358 evaluated in the current study are related to these microbial communities (Taylor et al. 2007a,

359 Taylor et al. 2007b). We observed significant trait diversity differences between sites, partially

360 driven by high trait evenness at Punta Caracol. Further analysis revealed that Saigon contained

361 sponges that were mostly HMA with high chlorophyll $a$ concentrations while the community at

362 Punta Caracol included species with a wide range of photosymbiont and overall microbial

363 abundances. The two traits investigated in the current study are correlated because most sponges

364 that have high photosymbiont abundance are considered to be HMA species. However, despite

365 the long-term use of the HMA/LMA classification recent research has made several aspects of

366 this dichotomy less clear by demonstrating that sponge species host a continuum of microbial 
367 diversity that is specific to a species and independent of microbial abundance classification

368 (Giles et al. 2013, Easson and Thacker 2014). Moreover, the function of the microbial

369 symbionts is likely more important than abundance and chlorophyll $a$ concentration is a better

370 predictor of metabolic differences among sponges than microbial abundance (Freeman, Easson

$371 \&$ Baker, 2014).

Decreased trait diversity at Saigon compared to Punta Caracol could imply that

373

374

375

376

377

378

379

380

381

382

ecological forces at this site are selecting for a sponge assemblage with particular functional traits. Most sponges that host photosynthetic microorganisms rely on them for nutrition to some degree (Thacker and Freeman 2012), and as a result may rely less on heterotrophic feeding. We originally hypothesized that poor water quality in the region (Collin 2005, D'Croz, Del Rosario, \& Gondola, 2005, Gochfeld, Schloder \& Thacker, 2007) would lead to increased particulate matter in the water column, potentially benefitting heterotrophic sponge species and selecting against phototrophic sponges (Weisz, Lindquist \& Martens, 2008). Instead, a higher abundance of species that host abundant symbionts, specifically, photosymbionts at Saigon may be driven by the ability of these symbionts to utilize diverse inorganic nutrient sources common in areas of anthropogenic input (Freeman et al., 2013; Easson et al. 2014; Zhang et al. 2015).

Chlorophyll $a$ concentration and microbial abundance are somewhat limited in what they can elucidate about the sponge function, and adding more traits to the analysis would be beneficial. One trait that would provide greater resolution for sponge community function would be nitrogen transformation potential of sponge symbionts. However, data for this trait is limited to a small number of sponge species, and uncertainty surrounding the stability of these symbiont communities, as well as measurement discrepancies within a single species, prevented us from 
389

390

evaluating these traits in the current study (Southwell 2007, Southwell et al. 2008, Hoffman et al. 2009, Maldonado, Ribes \& van Duyl, 2012, Fiore, Baker \& Lesser, 2013).

The current study shows that a sponge community in close proximity to human populations consisted of fewer sponge species with higher photosymbiont abundance, as well as, overall microbial abundance. In contrast, the community at a site distant from human development (Punta Caracol) included a more diverse assemblage of species, including those considered to have both high and low microbial abundance and chlorophyll $a$. Although we present no direct evidence of human impact (i.e. nutrient analysis), Gochfeld, Schloder \& Thacker, (2007) measured pollutants consistent with anthropogenic inputs in the Saigon area, and thus concluded that reefs in this region likely experience some degree of human impact. This, coupled with the fact that development in the Saigon area has continued (Figure 1), implies that Saigon has been chronically exposed to anthropogenic inputs for at least the last 7 years. Our observations of differences in species and phylogenetic diversity, altered species composition, and functional trait diversity at otherwise similar sites suggest that proximity to human development (and potentially these inputs) may be partially shaping the community composition of these dominant benthic invertebrates. Importantly, our data also suggest that this variation may have important impacts on genetic diversity and ecosystem function. For instance, while species with high photosymbiont abundance may increase local productivity, selection for species with abundant symbiont communities may lead to a reduction in heterotrophic feeding, instead favoring a community capable of diverse nitrogen transformations. Selection favoring HMA species over LMA species, which might rely more on heterotrophic feeding, might further alter the cycling of nutrients and organic matter within reef ecosystems by reducing water filtration rates. Thus, as shifts from coral-dominated systems to sponge-dominated systems are 
412 occurring throughout the Caribbean (Loh and Pawlik 2014), it is important for us to understand

413 how local-scale changes impact the composition of these sponge communities, as well as the

414 functional role of species within these communities.

415

\section{Acknowledgments}

417 We thank the staff of the Smithsonian Tropical Research Institute Bocas del Toro Research

418 station for their assistance in the field, as well as the participants in the Bocas del Toro Sponge

419 Course in 2012. Specifically we thank the instructors of this course Maria-Cristina Diaz,

420 Eduardo Hajdu, and Gisele Lôbo-Hajdu for helping the authors with identifying sponge species.

421 We also thank Marc Slattery and Deborah Gochfeld for their support of this research, Julia Korn

422 for help with data visualizations, and Taylor Roberge for manuscript feedback. All R code for

423 statistical analyses was obtained from portions of Steven Kembel's "Biodiversity Analysis in R"

424 workshop (http://kembellab.ca/r-workshop/biodivR/SK_Biodiversity_R.html).

425

426

427

428

429

430 


\section{Bibliography}

Alcolado, P. M. 2007. Reading the code of coral reef sponge community composition and structure for environmental biomonitoring: some experiences from Cuba. Porifera Research: Biodiversity, Innovation and Sustainability, Rio de Janeiro: Museu Nacional: 3-10.

Aris-Brosou S, Yang Z. 2003. Bayesian models of episodic evolution support a late Precambrian explosive diversification of the Metazoa. Molecular Biology and Evolution 20:19471954.

Aronson, R. B., \& Precht, W. F. 2001. White-band disease and the changing face of Caribbean coral reefs. In The Ecology and Etiology of Newly Emerging Marine Diseases (pp. 2538). Springer Netherlands.

Aronson, R., I. Macintyre, C. Wapnick, and M. O'Neill. 2004. Phase shifts, alternative states and the unprecedented convergence of two reef systems. Ecology 85:1876-1891.

Bell, J. J., Davy, S. K., Jones, T., Taylor, M. W., \& Webster, N. S. (2013). Could some coral reefs become sponge reefs as our climate changes? Global change biology, 19(9), 26132624.

Brock, W. A., and S. R. Carpenter. 2006. Variance as a leading indicator of regime shift in ecosystem services. Ecology and Society 11:9.

Cadotte, M. W. 2011. The new diversity: management gains through insights into the functional diversity of communities. Journal of Applied Ecology 48:1067-1069.

Carpenter, S., and W. Brock. 2006. Rising variance: a leading indicator of ecological transition. Ecology Letters 9:311-318.

Collin, R. 2005. Ecological Monitoring and Biodiversity Surveys at the Smithsonian Tropical Research Institute's Bocas del Toro Research Station. Caribbean Journal of Science 41:367-373.

D'Croz, L., J. B. Del Rosario, and P. Gondola. 2005. The effect of fresh water runoff on the distribution of dissolved inorganic nutrients and plankton in the Bocas del Toro Archipelago, Caribbean Panama. Caribbean Journal of Science 41:414-429.

de Goeij, J. M., D. van Oevelen, M. J. Vermeij, R. Osinga, J. J. Middelburg, A. F. de Goeij, and W. Admiraal. 2013. Surviving in a marine desert: the sponge loop retains resources within coral reefs. Science 342:108-110.

Diaz, M. C. 2005. Common sponges from shallow marine habitats from Bocas del Toro region, Panama. Caribbean Journal of Science 41:465-475.

Díaz, M. C., and K. Rützler. 2001. Sponges: An essential component of Caribbean coral reefs. Bulletin of Marine Science 69:535-546. 
472

473

474

475

476

477

478

479

480

481

482

483

484

485

486

487

488

489

490

491

492

493

494

495

496

497

498

499

500

501

502

503

504

505

506

507

508

509

510

511

512

513

514

515

516

Díaz, M. C., and B. B. Ward. 1997. Sponge-mediated nitrification in tropical benthic communities. Marine Ecology Progress Series 156:97-107.

Dudgeon, S. R., R. B. Aronson, J. F. Bruno, and W. F. Precht. 2010. Phase shifts and stable states on coral reefs. Marine Ecology Progress Series 413:201-216.

Easson, C. G., M. Slattery, D. M. Baker, and D. J. Gochfeld. 2014. Complex ecological associations: Evidence for competition and facilitation in a sponge-algal interaction. Marine Ecology Progress Series.

Easson, C. G., and R. W. Thacker. 2014. Phylogenetic signal in the community structure of hostspecific microbiomes of tropical marine sponges. Frontiers in microbiology 5.

Erwin, P., and R. Thacker. 2007. Incidence and identity of photosynthetic symbionts in Caribbean coral reef sponge assemblages. J Mar Biol Assoc U.K. 87:1683-1692.

Fang, J. K., C. H. Schönberg, M. A. Mello-Athayde, O. Hoegh-Guldberg, and S. Dove. 2014. Effects of ocean warming and acidification on the energy budget of an excavating sponge. Global Change Biology 20:1043-1054.

Fiore, C. L., D. M. Baker, and M. P. Lesser. 2013. Nitrogen Biogeochemistry in the Caribbean Sponge, Xestospongia muta: A Source or Sink of Dissolved Inorganic Nitrogen? PLoS ONE 8: 72961.

Freeman, C., and R. Thacker. 2011. Complex interactions between marine sponges and their symbiotic microbial communities. Limnology and Oceanography 56:1577-1586.

Freeman, C., R. Thacker, D. Baker, and M. Fogel. 2013. Quality or quantity: is nutrient transfer driven more by symbiont identity and productivity than by symbiont abundance? ISME J 7:1116-1125.

Freeman, C. J., C. G. Easson, and D. M. Baker. 2014. Metabolic diversity and niche structure in sponges from the Miskito Cays, Honduras. PeerJ 2:e695.

Giles, E. C., J. Kamke, L. Moitinho-Silva, M. W. Taylor, U. Hentschel, T. Ravasi, and S. Schmitt. 2013. Bacterial community profiles in low microbial abundance sponges. FEMS Microbiology Ecology 83:232-241.

Gloeckner, V., M. Wehrl, L. Moitinho-Silva, C. Gernert, P. Schupp, J. R. Pawlik, N. L. Lindquist, D. Erpenbeck, G. Wörheide, and U. Hentschel. 2014. The HMA-LMA dichotomy revisited: an electron microscopical survey of 56 sponge species. The Biological Bulletin 227:78-88.

Gochfeld, D., C. Easson, C. Freeman, R. Thacker, and J. Olson. 2012. Disease and nutrient enrichment as potential stressors on the Caribbean sponge Aplysina cauliformis and its bacterial symbionts. Marine Ecology Progress Series 456:101-111.

Gochfeld, D. J., C. Schloder, and R. W. Thacker. 2007. Sponge community structure and disease prevalence on coral reefs in Bocas del Toro, Panama. Porifera Research: Biodiversity, Innovation and Sustainability Custódio, M.R., Lôbo-Hajdu, G., Hajdu, E., and Muricy, G. (eds). Rio de Janeiro, Brazil: Museu Nacional:pp. 335-342.

Gotelli, N. J., \& Chao, A. (2013). Measuring and estimating species richness, species diversity, and biotic similarity from sampling data. Encyclopedia of biodiversity, 5, 195-211.

Graham, N. A., S. K. Wilson, S. Jennings, N. V. Polunin, J. P. Bijoux, and J. Robinson. 2006. Dynamic fragility of oceanic coral reef ecosystems. Proceedings of the National Academy of Sciences 103:8425-8429.

Guzman, H. M. 2003. Caribbean coral reefs of Panama: present status and future perspectives. Latin American coral reefs:241-274. 
517 Hadas, E., D. Marie, M. Shpigel, and M. Ilan. 2006. Virus predation by sponges is a new

$518 \quad$ nutrient-flow pathway in coral reef food webs. Limnology and Oceanography 51:15481550.

520

Harvell, D., E. Jordán-Dahlgren, S. Merkel, E. Rosenberg, L. Raymundo, G. Smith, E. Weil, and B. Willis. 2007. Coral disease, environmental drivers, and the balance between coral and microbial associates. Oceanography 20:172-195.

Hewitt, J. E., Thrush, S. F., \& Dayton, P. D. (2008). Habitat variation, species diversity and ecological functioning in a marine system. Journal of Experimental Marine Biology and Ecology, 366(1), 116-122.

Hoffman, F., R. Radax, D. Woebken, M. Holtappels, G. Lavik, H. T. Rapp, .,, M.-L. Schlappy, C. Schleper, and M. M. Kuypers. 2009. Complex nitrogen cycling in the sponge Geodia barretti. Environmental Microbiology 11:2228-2243.

Hughes, T. 1994. Catastrophes, phase shifts, and large-scale degradation of a Caribbean coral reef. Science 265:1547-1551.

Hughes, T., and J. Connell. 1999. Multiple stressors on coral reefs: A long-term perspective. Limnololgy and Oceanography. 443:932-940.

Ives, A. R., and M. R. Helmus. 2011. Generalized linear mixed models for phylogenetic analyses of community structure. Ecological Monographs 81:511-525.

Jackson, J. B., M. X. Kirby, W. H. Berger, K. A. Bjorndal, L. W. Botsford, B. J. Bourque, R. H. Bradbury, R. Cooke, J. Erlandson, and J. A. Estes. 2001. Historical overfishing and the recent collapse of coastal ecosystems. Science 293:629-637.

Jones, G. P., M. I. McCormick, M. Srinivasan, and J. V. Eagle. 2004. Coral decline threatens fish biodiversity in marine reserves. Proceedings of the National Academy of Sciences of the United States of America 101:8251-8253.

Kainer, D., \& Lanfear, R. (2015). The effects of partitioning on phylogenetic inference. Molecular biology and evolution, 32 (6): 1611-1627.

Katoh, K., K. Misawa, K. i. Kuma, and T. Miyata. 2002. MAFFT: a novel method for rapid multiple sequence alignment based on fast Fourier transform. Nucleic Acids Research 30:3059-3066.

Kaufmann, K. W., and R. C. Thompson. 2005. Water temperature variation and the meteorological and hydrographic environment of Bocas del Toro, Panama. Caribbean Journal of Science 41:392-413.

Kembel, S. W., and J. F. Cahill Jr. 2011. Independent evolution of leaf and root traits within and among temperate grassland plant communities. PLoS One 6:e19992.

Kembel, S. W., P. D. Cowan, M. R. Helmus, W. K. Cornwell, H. Morlon, D. D. Ackerly, S. P. Blomberg, and C. O. Webb. 2010. Picante: R tools for integrating phylogenies and ecology. Bioinformatics 26:1463-1464.

Lapointe, B. E. 1997. Nutrient thresholds for bottom-up control of macroalgal blooms on coral reefs in Jamaica and southeast Florida. Limnology and Oceanography 42:1119-1131.

Loh, T. L., and Pawlik, J. R. (2014). Chemical defenses and resource trade-offs structure sponge communities on Caribbean coral reefs. Proceedings of the National Academy of Sciences, 111(11), 4151-4156.

Maldonado, M., M. Ribes, and F. C. van Duyl. 2012. Nutrient Fluxes Through Sponges: Biology, Budgets, and Ecological Implications. Page 113 Advances in Marine Biology.

Maliao, R., R. Turingan, and J. Lin. 2008. Phase-shift in coral reef communities in the Florida Keys National Marine Sanctuary (FKNMS), USA. Marine Biology 154:841-853. 
563

564

565

566

567

568

569

570

571

572

573

574

575

576

577

578

579

580

581

582

583

584

585

586

587

588

589

590

591

592

593

594

595

596

597

598

599

600

601

602

603

604

605

606

607

608

McCook, L. J. 1999. Macroalgae, nutrients and phase shifts on coral reefs; scientific issues and management consequences for the Great Barrier Reef. Coral Reefs 18:357-367.

McMurray, S. E., T. P. Henkel, and J. R. Pawlik. 2010. Demographics of increasing populations of the giant barrel sponge Xestospongia muta in the Florida Keys. Ecology 91:560-570.

Miller, M. A., W. Pfeiffer, and T. Schwartz. 2010. Creating the CIPRES Science Gateway for inference of large phylogenetic trees. Pages 1-8 in Gateway Computing Environments Workshop (GCE), 2010. IEEE.

Moberg, F., and C. Folke. 1999. Ecological goods and services of coral reef ecosystems. Ecological economics 29:215-233.

Mumby, P. J., Broad, K., Brumbaugh, D. R., Dahlgren, C., Harborne, A. R., Hastings, A., ... \& Sanchirico, J. N. (2008). Coral reef habitats as surrogates of species, ecological functions, and ecosystem services. Conservation Biology, 22(4), 941-951.

Norström, A. V., M. Nyström, J. Lokrantz, and C. Folke. 2009. Alternative states on coral reefs: beyond coral-macroalgal phase shifts. Mar Ecol Prog Ser 376:295-306.

Nyström, M., C. Folke, and F. Moberg. 2000. Coral reef disturbance and resilience in a humandominated environment. Trends in Ecology and Evolution 15:413-417.

Oksanen, J., R. Kindt, P. Legendre, B. O’Hara, M. H. H. Stevens, M. J. Oksanen, and M. Suggests. 2007. The vegan package. Community ecology package.

Parsons, T. R., Y. Maita, and C. M. Lalli. 1984. A manual of chemical and biological methods for seawater analysis. Pergamon Press.

Pile, A., M. Patterson, and J. Witman. 1997. Finding Reiswig's missing carbon: quantification of sponge feeding using dual-beam flow cytometry. Pages 1403-1410 in Proceedings of the 8th international Coral Reef Symposium. Balboa, Panama: Smithsonian Tropical Research Institute.

Powell, A., D. J. Smith, L. J. Hepburn, T. Jones, J. Berman, J. Jompa, and J. J. Bell. 2014. Reduced diversity and high sponge abundance on a sedimented Indo-Pacific reef system: implications for future changes in environmental quality. PLoS One 9:e85253.

Redmond, N., C. Morrow, R. Thacker, M. Diaz, N. Boury-Esnault, P. Cárdenas, E. Hajdu, G. Lôbo-Hajdu, B. Picton, and S. Pomponi. 2013. Phylogeny and Systematics of Demospongiae in Light of New Small-Subunit Ribosomal DNA (18S) Sequences. Integrative and Comparative Biology:ict078.

Reiswig, H. M. 1971. Particle feeding in natural populations of three marine demosponges. The Biological Bulletin 141:568-591.

Ronquist, F., M. Teslenko, P. van der Mark, D. L. Ayres, A. Darling, S. Höhna, B. Larget, L. Liu, M. A. Suchard, and J. P. Huelsenbeck. 2012. MrBayes 3.2: efficient Bayesian phylogenetic inference and model choice across a large model space. Systematic biology 61:539-542.

Safi, K., M. V. Cianciaruso, R. D. Loyola, D. Brito, K. Armour-Marshall, and J. A. F. DinizFilho. 2011. Understanding global patterns of mammalian functional and phylogenetic diversity. Philosophical Transactions of the Royal Society B: Biological Sciences 366:2536-2544.

Schlacher, T. A., Schlacher-Hoenlinger, M. A., Williams, A., Althaus, F., Hooper, J. N., \& Kloser, R. 2007. Richness and distribution of sponge megabenthos in continental margin canyons off southeastern Australia. Marine Ecology Progress Series, 340, 73-88.

Southwell, M. W. 2007. Sponge impacts on coral reef nitrogen cycling, Key Largo, Florida. Ph.D. thesis, University of North Carolina at Chapel Hill. 
609

610

611

612

613

614

615

616

617

618

619

620

621

622

623

624

625

626

627

628

629

630

631

632

633

634

635

636

637

638

639

640

641

642

643

644

645

646

647

648

649

650

651

652

Southwell, M. W., J. B. Weisz, C. S. Martens, and N. Lindquist. 2008. In situ fluxes of dissolved inorganic nitrogen from the sponge community on Conch Reef, Key Largo, Florida. Limnology and Oceanography 53:986-996.

Stuart-Smith, R. D., A. E. Bates, J. S. Lefcheck, J. E. Duffy, S. C. Baker, R. J. Thomson, J. F. Stuart-Smith, N. A. Hill, S. J. Kininmonth, and L. Airoldi. 2013. Integrating abundance and functional traits reveals new global hotspots of fish diversity. Nature 501:539-542.

Stuart-Smith, R. D., A. E. Bates, J. S. Lefcheck, J. E. Duffy, S. C. Baker, R. J. Thomson, J. F. Stuart-Smith, N. A. Hill, S. J. Kininmonth, and L. Airoldi. 2015. The potential of traitbased approaches to contribute to marine conservation. Marine policy 51:148-150.

Taylor, M. W., R. T. Hill, J. Piel, R. W. Thacker, and U. Hentschel. 2007a. Soaking it up: the complex lives of marine sponges and their microbial associates. The ISME journal 1:187190.

Taylor, M. W., R. Radax, D. Steger, and M. Wagner. 2007b. Sponge associated microorganisms: evolution, ecology, and biotechnological potential. Microbiology and Molecular Biology Reviews 71:295-347.

Thacker, R., and C. Freeman. 2012. 2 Sponge-microbe symbioses: recent advances and new directions. Advances in Marine Biology 62:57-112.

Thacker, R. W., A. L. Hill, M. S. Hill, N. E. Redmond, A. G. Collins, C. C. Morrow, L. Spicer, C. A. Carmack, M. E. Zappe, and D. Pohlmann. 2013. Nearly complete 28S rRNA gene sequences confirm new hypotheses of sponge evolution. Integrative and Comparative Biology 53:373-387.

Weisz, J., U. Hentschel, N. Lindquist, and C. Martens. 2007. Linking abundance and diversity of sponge-associated microbial communities to metabolic differences in host sponges. Marine Biology 152:475-483.

Weisz, J. B., N. Lindquist, and C. S. Martens. 2008. Do associated microbial abundances impact marine demosponge pumping rates and tissue densities? Oecologia 155:367-376.

Wiens JJ and Morrill MC. 2011. Missing Data in Phylogenetic Analysis: Reconciling Results from Simulations and Empirical Data. Systematic Biology 60(5):719-731

Wilkinson, C. R. 1983. Net primary productivity in coral reef sponges. science 219:410-412.

Wilkinson, C. R. 1992. Symbiotic interactions between marine sponges and algae. Algae and Symbioses:112-151.

Wilkinson, C. R., and P. Fay. 1979. Nitrogen fixation in coral reef sponges with symbiotic cyanobacteria. Nature 279:527-529.

Witman, J. D., Etter, R. J., \& Smith, F. (2004). The relationship between regional and local species diversity in marine benthic communities: a global perspective. Proceedings of the National Academy of Sciences of the United States of America, 101(44), 15664-15669.

Wulff, J. 2001. Assessing and monitoring coral reef sponges: Why and how? Bulletin of Marine Science: Proceedings of International Conference on Scientific Aspects of Coral Reef Assessment, Monitoring, and Restoration 69:831-846.

Wulff, J. L. (2006). Rapid diversity and abundance decline in a Caribbean coral reef sponge community. Biological Conservation, 127(2), 167-176.

Wulff, J. (2013). Recovery of sponges after extreme mortality events: morphological and taxonomic patterns in regeneration versus recruitment. Integrative and comparative biology, 53(3), 512-523. 
653 Yahel, G., J. H. Sharp, D. Marie, C. Häse, and A. Genin. 2003. In situ feeding and element 654 removal in the symbiont-bearing sponge Theonella swinhoei: Bulk DOC is the major source for carbon. Limnology and Oceanography:141-149.

Zea, S. 1994. Patterns of coral and sponge abundance in stressed coral reefs at Santa Marta, Colombian Caribbean. Sponges in time and space. Balkema, Rotterdam:257-264.

Zhang, F., L. C. Blasiak, J. O. Karolin, R. J. Powell, C. D. Geddes, and R. T. Hill. 2015. Phosphorus sequestration in the form of polyphosphate by microbial symbionts in marine

661

662

663

664 


\section{1}

Map of Bocas del Toro Region in Panama

Figure 1: Map of Bocas del Toro region in Panama, where surveys were performed (Punta Caracol and Saigon Bay). The white dot marked STRI represents the Smithsonian Tropical Research Institute. Each yellow dot represents an individual structure (residence) in 2004, and each red dot represents a structure in 2011. Blue dots represent new residences that were built between 2004 and 2011. Approximately 55 new structures were constructed on or adjacent to the shore along Saigon Bay in this 7-year span. Imagery is from 2004 (left map) and 2011 (middle and right maps) and is provided by DigitalGlobe ${ }^{\circledast}$ via Google Earth and $\operatorname{ArcGIS}^{\circledast}$ software imagery basemap in $\operatorname{ArcMap}^{T M}$ by Esri ${ }^{\circ}$.

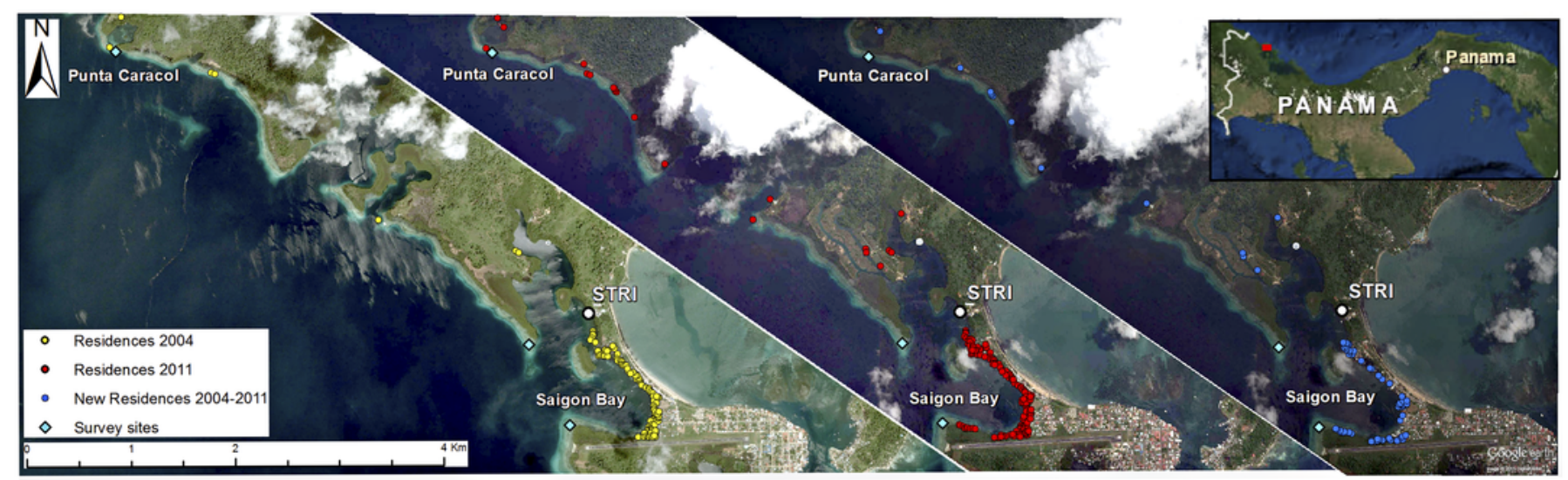




\section{Figure 2 (on next page)}

Figure 2 Relative abundance heatmap

Figure 2: Relative abundance heatmap of sponge species encountered within each transect. These data are square-root transformed for easier visualization. A Bray-Curtis dissimilarity dendrogram on the left highlights the taxonomic dissimilarity among transects. The reconstructed phylogeny of these sponge species is displayed across the top, and species names are displayed across the bottom. S(1-9) represent transects near Saigon Bay, which are closer to a larger number of residences, while PC(1-10) represent transects at Punta Caracol. 


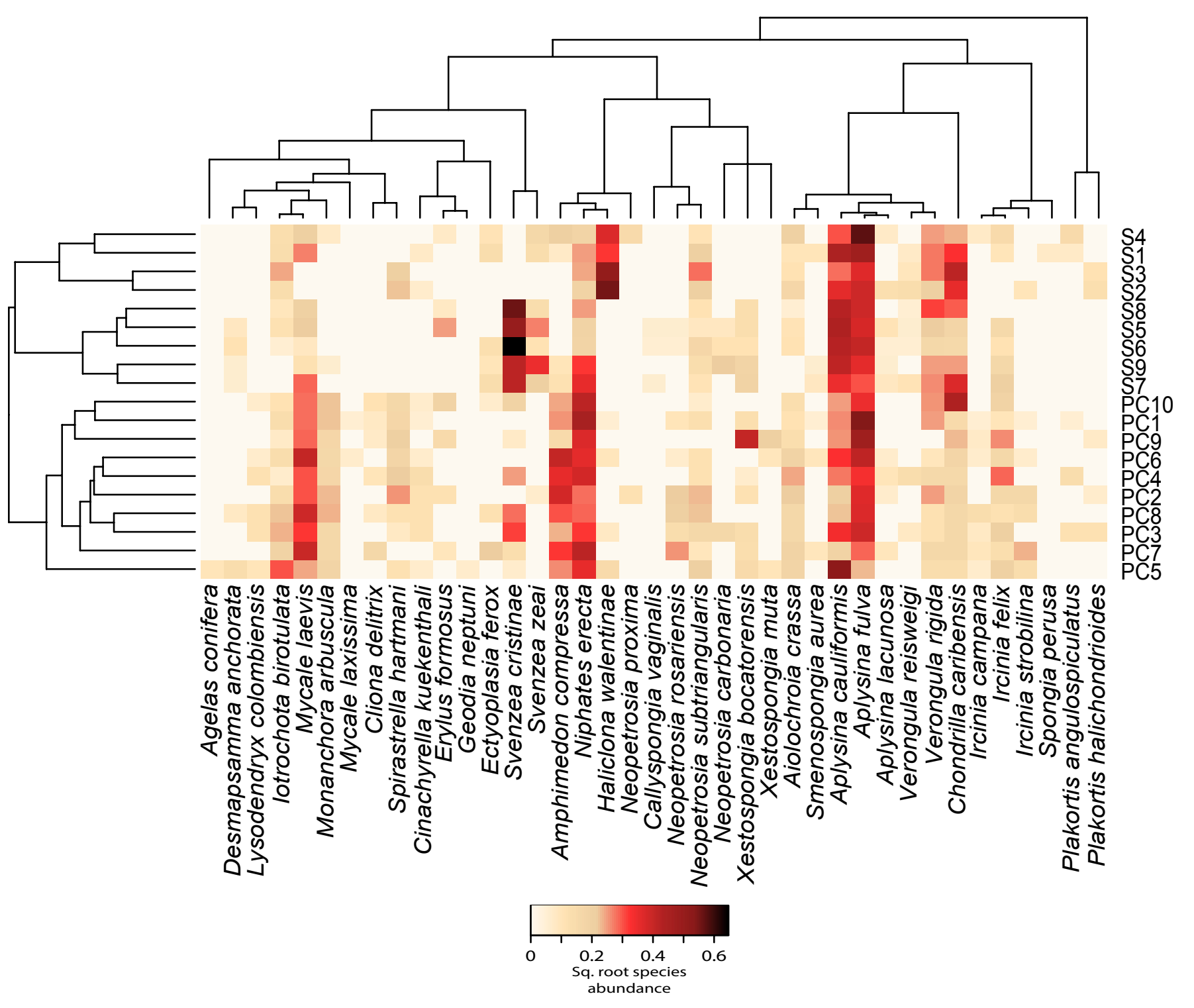


3

NMDS scaling plots for beta diversity metrics

Figure 3: Nonmetric multi-dimensional scaling plots of (A) BCD taxonomic, (B) MPD phylogenetic, (C) MNTD phylogenetic, and (D) trait dissimilarity between sites. Blue dots indicate transects at Saigon, while red dots indicate transects at Punta Caracol.

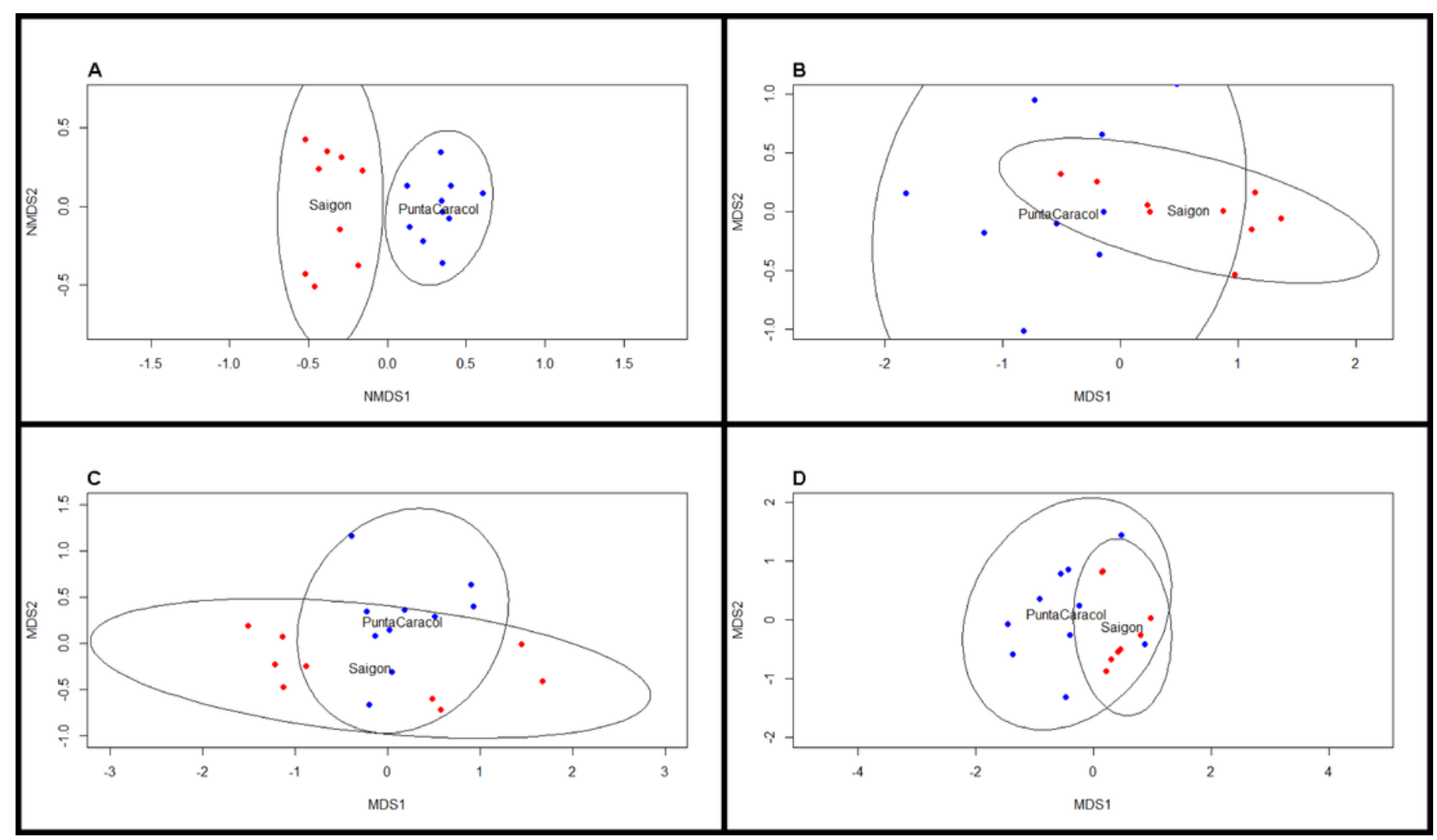

